\title{
The Physiology of Volume Resuscitation
}

\author{
Paul E. Marik
}

Published online: 10 September 2014

(C) Springer Science + Business Media New York 2014

\begin{abstract}
Currently static and dynamic indices of fluid responsiveness are used to guide fluid resuscitation. The physiological effect of a fluid bolus is considered in terms of the Frank-Starling mechanism. This is, however, an incomplete concept and ignores the effect of the venous system. This paper reviews the interplay between the stressed and unstressed volume, the mean circulatory filling pressure and the central venous pressure in determining organ and microcirculatory flow. We also review method for determining fluid responsiveness.
\end{abstract}

Keywords Intravascular volume $\cdot$ Stressed volume Fluid responsiveness - Central venous pressure · Venous return $\cdot$ Stroke volume

\section{Introduction}

Shock is currently defined as "circulatory failure that results in cellular oxygen deficit." [1] This definition is problematic as oxygen delivery $\left(\mathrm{DO}_{2}\right)$ has to fall to very low levels before oxygen consumption $\left(\mathrm{VO}_{2}\right)$ falls and most patients with "shock" have normal levels of oxygen consumption. Ronco et al. determined the critical oxygen delivery threshold for anaerobic metabolism in critically ill humans, while life support was being discontinued [2]. In this study, the critical oxygen delivery threshold was $3.8 \pm 1.5 \mathrm{ml} /(\mathrm{kg} \mathrm{min})(266 \mathrm{ml} / \mathrm{min}$ in a $70 \mathrm{~kg}$ patient $)$. Similarly, in a remarkable and rather unconventional study,

\section{P. E. Marik $(\square)$}

Division Pulmonary and Critical Care Medicine, Eastern Virginia Medical School, 825 Fairfax Av, Suite 410, Norfolk, VA 23507, USA

e-mail: marikpe@evms.edu van Woerkens et al. studied the relationship between $\mathrm{VO}_{2}$ and $\mathrm{DO}_{2}$ in a Jehovah Witness patient who was bleeding to death [3]. In this patient $\mathrm{VO}_{2}$ became supply dependent below a $\mathrm{DO}_{2}$ of $4.9 \mathrm{ml} /(\mathrm{kg} \mathrm{min})(343 \mathrm{ml} / \mathrm{min}$ in a $70 \mathrm{~kg}$ man). Shibutani et al. studied the relationship between $\mathrm{VO}_{2}$ and $\mathrm{DO}_{2}$ in 58 patients undergoing cardiopulmonary bypass [4]. The critical value of $\mathrm{DO}_{2}$ was identified to be $330 \mathrm{ml} / \mathrm{min}$. These values translate into a cardiac output of approximately $2 \mathrm{l} / \mathrm{min}$; it is likely that only pre-terminal moribund patients with "shock" would have such a low cardiac output. While an elevated lactate concentration is widely believed to be a marker of inadequate tissue perfusion, inadequate cellular oxygen delivery, and anaerobic metabolism, an overwhelming body of evidence suggests that in most clinical situations lactate is produced aerobically as part of the stress response [5॰]. Furthermore, attempts at increasing $\mathrm{DO}_{2}$ in patients with sepsis and an elevated lactate level does not increase $\mathrm{VO}_{2}[6,7]$, and this approach is associated with an increased risk of death [8]. While it is unclear how best to define shock, we believe "circulatory shock" is best defined as "a potentially life threatening reduction in organ blood flow."

\section{Determinant of Organ Blood Flow}

The mean arterial pressure (MAP) is an important determinant of organ blood flow. When the MAP falls below an organs autoregulatory range there is an almost linear fall in organ blood flow [9]. The fall in blood flow is likely to occur at a higher blood pressure in patients with longstanding hypertension due to a shift in the autoregulatory range to the right. Furthermore, different vascular beds will lose autoregulation at different blood pressure values. For example, the mammalian kidney does so at a MAP of about $70 \mathrm{mmHg}$, the brain at between 60 and $70 \mathrm{~mm} \mathrm{Hg}$, while 
the coronary circulation requires a MAP of about $50-55 \mathrm{mmHg}$ [9-11]. Cardiac output (CO) and total peripheral resistance (TPR) are the major factors determining MAP $(\mathrm{MAP}=\mathrm{CO} / \mathrm{TPR})$. Stroke volume $(\mathrm{SV})$ in turn, in older children and adults, is the major determinant of $\mathrm{CO}(\mathrm{CO}=\mathrm{SV} \times$ heart rate $)$ and is determined by left ventricular contractility and left ventricular end-diastolic volume (LVEDV). LVEDV by the Frank-Starling mechanism is a major determinant of SV. According to the Frank-Starling principle as LVEDV (or preload) increases left ventricular SV increases until the optimal preload is achieved at which point the SV remains relatively constant. This optimal preload is related to the maximal overlap of the actin-myosin myofibrils. It is important to note that in an intact heart, the actin-myosin links cannot be disengaged and hence there is no descending limb of the FrankStarling curve. In normal physiologic conditions, both ventricles operate on the ascending portion of the FrankStarling curve [12].

The amount of blood pumped out of the heart (cardiac output) is equivalent to venous return (volume entering right atria) [13]. According to Guyton, venous return is determined by the pressure gradient between the peripheral veins and the right atrium (CVP), as well as the resistance to venous return [14]. Due to the high compliance of the venous system, venous resistance is very low and for this discussion can be ignored. Organ blood flow is driven by the difference in the pressure between the arterial and venous sides of the circulation. The MAP minus the CVP is, therefore, the driving force for organ blood flow, while the difference between post-arteriolar and venular pressure determines microcirculatory flow. However, right atrial pressure (CVP) is transmitted backwards, increasing venous pressure. A high venous pressure dramatically impedes organ and microcirculatory flow (discussed below). Therefore, the interplay between the pressure gradient for venous return and the CVP plays a major role in determining organ blood flow.

The heart can only pump that volume of blood into the arterial system which equals the volume of venous return [13]. Therefore, venous return becomes the major factor determining cardiac output. Venous return is determined by the pressure gradient between the peripheral veins and the right atrium [13]. As approximately $70 \%$ of the blood volume is within the venous system, changes in venous blood volume play a major role in determining venous return, and therefore, cardiac output. The venous system can be divided into two theoretical compartments, the unstressed and stressed volume [15]. The intravascular volume that fills the venous system to the point where intravascular pressure starts to rise is called unstressed volume, whereas the volume that stretches the veins and causes intravascular pressure to rise is called the stressed volume. The stressed blood volume is the major contributor of venous pressure, and therefore, venous return. The unstressed volume normally accounts for about $75 \%$ of the venous blood volume $[15,16]$. The venous system, therefore, acts as a reservoir that can rapidly recruit blood from the unstressed blood compartment to maintain venous return to the right heart. Splanchnic and cutaneous veins are highly compliant and represent the largest blood volume reservoirs. The veins of the extremities are less compliant making a smaller contribution to the blood volume reservoir $[15,16]$. This suggests that the volume of blood in the legs is subject to less variability than that of other vascular beds. This observation has important implications for the performance of a passive leg-raising maneuver (PLR), [17] which would theoretically provide a stable and calibrated volume infusion.

The mean circulatory filling pressure is conceptualized as the pressure distending the vasculature, when the heart is stopped (zero flow) and the pressures in all segments of the circulatory system have equalized $[15,16]$. The mean circulatory filling pressure was first described by Bayliss and Starling in a dog model during cardiac arrest [18]. The mean circulatory filling pressure is regarded as the driving pressure that determines venous return and is considered synonymous with the effective circulatory blood volume $[15,16]$. The mean circulatory filling pressure in humans is normally in the range of $8-10 \mathrm{mmHg}[15,16]$. As the venous system is largest component of the vacular system, the stressed venous system is the major contributor to the mean circulatory filling pressure, with the mean venous pressure being slightly below that of the mean circulatory filling pressure $(6-8 \mathrm{mmHg})$. The anatomic site where vascular pressure is equivalent to the mean circulatory filling pressure is generally believed to be in the postcapillary small venules. This concept is supported by the studies of Sheldon et al. In a canine hemorrhagic shock model, these authors demonstrated that the peripheral postcapillary venous pressure was an accurate indicator of the effective blood volume and cardiac output [19, 20]. Guyton noted that an increase in blood volume increased the mean circulatory filling pressure, while the resistance to venous return decreased because of distension of the veins [21]. Therefore, the driving force for venous return is determined by the difference between the mean systemic filling pressure and the CVP. As the normal right atrial pressure (CVP) is about $2 \mathrm{mmHg}$, the pressure gradient determining venous return is normally approximately 6-8 mmHg. An increase in the CVP or a fall in the mean circulatory filling pressure will reduce venous return, $\mathrm{SV}$, and cardiac output. Furthermore, an increase in the CVP has a major effect on reducing organ blood flow (see below). Therefore, factors that determine organ perfusion include the stressed and unstressed venous volume, mean 
systemic filling pressure, and right atrial pressure (CVP), as well as cardiac function. Importantly, volume status and fluid responsiveness are not synonymous. A hypovolemic patient will increase cardiac output in response to fluid loading only, when the stressed blood volume increases and when the increase in the gradient between stressed blood volume (mean circulatory filling pressure) and CVP increases. Venoconstriction causes some of the unstressed volume to be shifted to the stressed volume thereby increasing venous pressure. Splanchnic and cutaneous veins are highly innervated by $\alpha-1$ receptors [22]. Furthermore, venous capacitance vessels are much more sensitive to sympathetic stimulation than are arterial resistance vessels. Vasopressors, therefore, mobilize blood from the unstressed reservoirs in the splanchnic circulation and skin, thereby increasing venous return and cardiac output. In a porcine endotoxic shock model, Datta and Magder demonstrated that norepinephrine increased the mean systemic filling pressure leading to an increase in venous return [23]. Similarly in patients with septic shock, Persichini et al. demonstrated that decreasing the dose of norepinephrine decreased the mean systemic filling pressure with a decrease in venous return and cardiac output [24]. In this study, a PLR maneuver increased the cardiac index to a greater degree at the lower dose of norepinephrine $(8 \pm 4$ vs $1 \pm 4 \%, p=0.001$ ), suggesting an increase in unstressed blood volume when the dosage of norepinephrine was reduced. These authors have also demonstrated that increasing the dose of norepinephrine decreased the effects of PLR on cardiac index [25].

Anesthesia may decrease venous return through multiple mechanisms. During surgical procedures, blood loss and fluid sequestration due to tissue injury may decrease total blood volume. Neuraxial anesthesia and systemic sedation blunt the compensatory circulatory reflexes that preserve stressed blood volume and mean circulatory filling pressure. Positive pressure ventilation compounds this problem by raising intra-thoracic pressure and decreasing the gradient that drives venous return [26]. Pneumoperitoneum and head up positioning during laparoscopy can also decrease the pressure gradient [27]. Fluid resuscitation during anesthesia can help preserve the gradient for venous return - but only if it increases stressed blood volume and mean circulatory filling pressure. Clinical studies show that fluid resuscitation maintains cardiac output during neuraxial anesthesia [28]. Fluid resuscitation may also attenuate the effect of positive pressure ventilation on venous return. If the splanchnic venous reservoir is volume expanded, its pressure may rise in parallel with intra-thoracic pressure [29]. Exogenous catecholamines with venoconstricting properties can also increase stressed blood volume to raise mean systemic filling pressures and increase cardiac output [30-32].
The Hazards of a High Central Venous Pressure

In addition to influencing venous return, a high CVP is transmitted retrograde, increasing venous pressure. Since organ blood flow is related to the difference between the MAP and organ pressure, an increase in CVP is associated with a fall in organ blood flow. This has a major effect on microcirculatory flow and organ function. Increased venous pressure increases the interstitial pressure of encapsulated organs such as the kidney and liver, reducing organ blood flow [33•]. The kidney is particularly affected by increased interstitial pressure resulting in a significant fall in glomerular filtration rate, and greatly impacting the pressure differential across Bowman's capsule [33•]. The detrimental effect of high venous pressure on renal function was established by Winton in an elegant set of experiments performed in 1930s [34]. This investigator attached the kidneys of a dog to a heart-lung circulation by means of cannulae inserted into the artery and veins of kidneys and then independently altered venous and arterial pressure. In these experiments, an increase in venous pressure dramatically decreased renal function. A number of studies in patients with sepsis and heart failure have demonstrated a high CVP to be the only hemodynamic parameter predictive of renal failure [35-37]. Legrand et al. noted a near linear relationship between increasing CVP and acute renal failure, with a CVP of $15 \mathrm{mmHg}$ being associated with an $80 \%$ risk of renal failure compared to $30 \%$ at a CVP of $6 \mathrm{mmHg}$ [38]. In a study of patients with sepsis, Vellinga et al. demonstrated that the sublingual microvascular flow index (MFI) and percentage of perfused vessels (PPV) were significantly lower with a patients with a high CVP ( $>12 \mathrm{mmHg}$ ) than a low CVP: $1.44 \pm 0.94$ vs. $1.89 \pm 0.91, p=0.006 ;$ and $88 \pm 21$ vs. $95 \pm 8 \%$, $p=0.006$ ). In a multivariate logistic regression analysis, the only significant predictor for an abnormal MFI was a CVP $>12 \mathrm{mmHg}$. Because microcirculatory driving pressure is the difference between post-arteriolar minus venular pressure, a relatively mild increase in CVP may considerably influence the capillary perfusion pressure and microcirculatory flow [39]. These data suggest that changes in venous pressure have a much greater effect on microcirculatory flow than the MAP. Furthermore, as long as the MAP is within an organs autoregulatory range, the CVP becomes the major determinant of organ blood flow.

Increased cardiac filling pressures following aggressive fluid resuscitation increase the release of natriuretic peptides [40, 41]. Natriuretic peptides cleave membrane-bound proteoglycans and glycoproteins (most notably syndecan-1 and hyaluronic acid) off the endothelial glycocalyx [4244]. The glycocalyx plays a major role in determining the vascular barrier function, preventing large macromolecules and fluid moving across the endothelium. An intact 
endothelial glycocalyx is a prerequisite of a functioning vascular barrier [45*0]. Damage to the glycocalyx profoundly increases endothelial permeability. In addition, increased natriuretic peptides inhibit the lymphatic propulsive motor activity reducing lymphatic drainage [4648]. Natriuretic peptides therefore function to sequestrate fluid into the interstitium in states of volume overload. In addition, it is important to recognize that only about $20 \%$ of the volume of a crystalloid bolus remains intravascular [49]. Large volume fluid resuscitation results in severe tissue edema. Tissue edema reduces oxygen and metabolite diffusion, alters tissue architecture, compromises capillary blood flow, impacts bowel function, and lymphatic drainage while disturbing cell-cell interactions, resulting in progressive organ dysfunction [33].

\section{Fluid Responsiveness}

An increase in venous return will only increase SV in a patient who is biventricular preload responsive. Multiple studies across diverse groups of hemodynamically unstable patients have demonstrated that only about $50 \%$ of patients are volume responsive. Fluid loading may fail to increase SV in:

(1) Vasodilated patients where the fluid fails to increase venous pressure. This may occur due to an inadequate volume of infused fluid.

(2) In patients' in whom there is a parallel increase in CVP and mean systemic filling pressure.

(3) In patients who are preload unresponsive (on the flat portion of Frank-Starling curve).

Low-dose vasoconstrictors should be considered in vasodilated fluid non-responders; such an intervention will decrease the capacitance of the unstressed blood volume increasing the likelihood of responding to additional fluid boluses. Fluid loading is likely to be particularly harmful in fluid non-responders particularly in those in whom CVP increases significantly following the fluid bolus.

The goal of fluid resuscitation is to normalize organ blood flow. This requires an increase in SV and cardiac output with a minimal increase in CVP. The dynamic interactions of fluid loading on the venous pressure, venous return and SV, and CVP determine whether a fluid bolus will be helpful or harmful. In patients who are fluid responsive (increase of stoke volume by at least $10 \%$ ), fluid loading increases the stressed blood volume, which then increases mean systemic filling pressure (or venous pressure) such that the increase in mean systemic filling pressure is greater than the increase in the CVP. In patients who are on the ascending Frank-Starling curve, and have normal left ventricular compliance, the heart is able to minimize the increase in the CVP by increasing the end- diastolic volume and subsequently the SV. In such circumstances, the pressure gradient to venous return increases in a preload responsive patient and SV increases. However, in patients with diastolic dysfunction and in patients who are near the top of the Frank-Starling curve the CVP increases in parallel to the mean systemic filling pressure and venous return remains unchanged. The increase in the CVP in these patients serves to compromise organ blood flow.

Hemodynamic interventions are assumed to have discrete measurable effects. Currently the physiological effect of a fluid bolus is considered in terms of the Frank-Starling mechanism and the change in SV. However, this is an incomplete concept and ignores the effect of the venous system $[13,50]$. Cecconi et al. investigated the relationship between the changes in mean systemic filling pressure with the change in CVP and SV following a fluid challenge in postsurgical ICU patients [51••]. In this study, mean systemic filling pressure increased equally in fluid responders and non-responders $(3.1 \pm 1.9$ vs $3.1 \pm 1.8 \mathrm{mmHg})$. However, the increase in the CVP was greater in the nonresponders than the responders with an increase in the venous pressure gradient recorded only in the responders. This suggests that the hearts of the non-responders were unable to accommodate the increase in volume without a large increase in filling pressure. This study elegantly reinforces the concept of the interplay between the venous pressure gradient and the Frank-Starling mechanism in determining the response to a fluid challenge. This finding supports the concept of the interaction between the FrankStarling and Marik-Phillips curves [52], such that as the patient "climbs up" the Frank-Starling curve the increment in SV decreases while extravascular lung water (EVLW) increases with increasing filling pressures (see Fig. 1). In addition, independent of the effect of fluid loading on cardiac output, an increase in CVP profoundly reduces organ blood flow. This "new" paradigm would suggest that clinicians monitor both the change in CVP, as well as SV during a fluid challenge. A disproportionate increase in the CVP may reduce venous return while at the same time compromising organ blood flow.

Conventional teaching and widely disseminated guidelines suggest that aggressive fluid resuscitation is the best initial approach to the patient with hemodynamic instability [1, 53, 54]. However, over the last decade it has become clear that aggressive fluid resuscitation is associated with increased morbidity and mortality across diverse populations of patients. Furthermore, multiple studies in patient's sepsis with, as well as surgical and trauma patients have demonstrated that a conservative fluid strategy is associated with improved patient outcomes [55, 56, 57•, 58]. "The Fluid Expansion as Supportive Therapy (FEAST)" study provides the most compelling data that a 


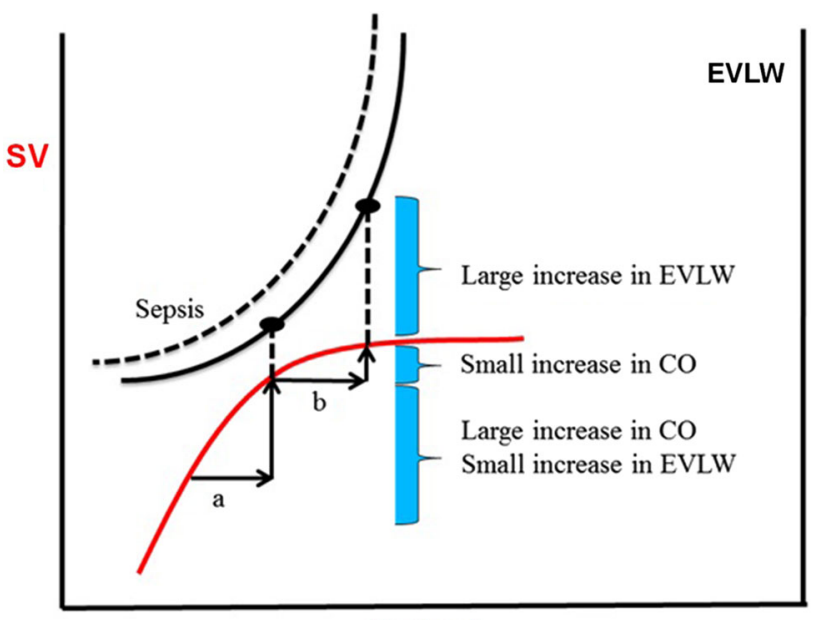

Preload

Fig. 1 Superimposition of the Frank-Starling and Marik-Phillips curves demonstrating the effects of increasing preload on SV and lung water in a patient who is preload responsive (a) and non-responsive (b). With sepsis the EVLW curve is shifted to the left. EVLW extravacular lung water, $C O$ cardiac output, $S V$ stroke volume. Reproduced from [52], with Permission form Oxford University Press

conservative fluid strategy improves patient outcomes [59••]. FEAST was a large rigorously performed study that randomized 3141 sub-Saharan children with severe sepsis to aggressive fluid loading or maintenance fluid only [59••]. In this study, aggressive fluid loading was associated with a significantly increased risk of death. Furthermore, there was no subgroup of patients that benefited from aggressive fluid resuscitation [60]. A review of the physiology of volume resuscitation, as well as a large body of clinical outcomes data suggests that the clinician should administer intravenous fluids with much trepidation. The first description of the use of intravenous fluid in a human is attributed to Dr Thomas Latta during the Cholera epidemic in London in 1832. Dr Latta described his experience in a letter to the editor of the Lancet where he comments "having no precedence to guide me I injected ounce after ounce of fluid closely observing the patient" [61]. The technique of fluid resuscitation described by Dr Latta nearly 200 years ago has stood the test of time and is currently the only rational method of fluid resuscitation... give small volumes of fluid and observe the patient (what a remarkable concept). The idea of giving large fluid boluses of $20-30 \mathrm{ml} / \mathrm{kg}$ to humans may violate the maxim, primum non nocere, and likely to lead to severe volume overload with an increased risk of complications and death [53]. Fluid resuscitation is best performed by giving patients 250-500 ml boluses of crystalloid (preferably Lactated Ringers solution), determining if other therapeutic interventions such as vasoconstrictors and inotropes are needed, and closely monitoring the response.
Determining Fluid Responsiveness

Abundant evidence demonstrates that pulmonary capillary wedge pressure and central venous pressure do not reliably predict fluid responsiveness [62•,63]. Trans-esophageal echocardiography can evaluate respirophasic variation of the superior vena cava. One study demonstrated that a passive breath delivered by mechanical ventilation will collapse the superior vena cava as it enters the thorax in fluid responsive patients with severe sepsis $[64,65]$. Respirophasic effects on arterial pulse pressure can also help predict the response to a fluid bolus. The arterial waveform is analyzed, while the ventilator delivers a $>8 \mathrm{ml} / \mathrm{kg}$ breath to a passive patient. The rise in intra-thoracic pressure can reduce venous return. Left ventricular filling will transiently rise due to ventricular interdependence and then fall. In fluid responsive patients, both ventricles are responsive to changes in venous return. Left ventricular $\mathrm{SV}$, therefore, will rise and fall with each inspiration [66]. Arterial pulse pressure is an indicator of SV if aortic compliance is constant. Therefore, pulse pressure variation, calculated from an arterial waveform, of greater than $12 \%$ predicts fluid responsiveness [67]. This test is unreliable if the patient has arrhythmias, tachypnea, or right heart failure $[67,68]$. As with all diagnostic tests, clinicians must consider the cut-off value. Setting a higher threshold for SV variation will decrease the false positive results (false prediction of fluid responsiveness). Clinicians should consider using a higher cutoff of variation $(>13 \%)$ when the risk of fluid resuscitation is high [69]. The strict conditions for performing stroke and pulse pressure variation tests are more likely present during general anesthesia than in critically ill patients. Another dynamic predictor of fluid responsiveness is the passive leg raise. This maneuver can be conducted on negative or positive pressure ventilation [70]. The clinician measures the SV response to transiently increasing the gradient for venous return. An increase of SV greater than $10 \%$ predicts fluid responsiveness [71].

\section{Conclusion}

Fluid resuscitation should be limited to patients who are likely to increase their SV by at least $10 \%$ following a fluid challenge. As patients' "ascend" the Frank-Starling curve, filling pressures increase (including the CVP), decreasing the pressure gradient for venous return limiting further increases in SV. High filling pressures are transmitted backwards increasing venous pressure which compromise microcirculatory and organ perfusion. Furthermore, high filling pressures increase EVLW and increase the release of natriuretic peptides. Natriuretic peptides in turn damage the 
endothelial glycocalyx and impede lymphatic drainage, sequestrating fluid into the interstitium. A liberal fluid approach which targets a CVP of greater than $8 \mathrm{mmHg}$ has been associated with an increased risk of organ dysfunction and poor outcomes. Consequently, we suggest a conservative strategy to fluid resuscitation across a broad spectrum of clinical disorders.

Acknowledgments This article was reviewed by Dr. Kumar Belani of the University of Minnesota. The author thanks Dr. David A. Berlin for his guidance and input throughout the preparation of this article.

\section{Compliance with Ethics Guidelines}

Conflict of Interest The authors have no financial interest in any of the products mentioned in this paper. Paul E. Marik declares that he has no conflict of interest.

Human and Animal Rights and Informed Consent This article does not contain any studies with human or animal subjects performed by any of the authors.

\section{References}

Papers of particular interest, published recently, have been highlighted as:

- Of importance

•- Of major importance

1. Vincent JL, De Backer D. Circulatory shock. N Engl J Med. 2013;369:1726-34

2. Ronco JJ, Fenwick JC, Tweeddale MG, et al. Identification of the critical oxygen delivery for anaerobic metabolism in critically ill septic and nonseptic humans. JAMA. 1993;270:1724-30.

3. van Woerkens EC, Trouwborst A, van Lanschot JJ. Profound hemodilution: what is the critical level of hemodilution at which oxygen delivery-dependent oxygen consumption starts in an anesthetized human? Anesth Analg. 1992;75:818-21.

4. Shibutani K, Komatsu T, Kubal K, et al. Critical level of oxygen delivery in anesthetized man. Crit Care Med. 1983;11:640-3.

5. - Garcia-Alvarez M, Marik PE, Bellomo R. Stress Hyperlactemia; present understanding and controversy. Lancet Endo Diabetes 2013; 2:339-47. This paper reviews the current understanding of the physology of lacate metabolism and dispells many myths on this topic.

6. Ronco JJ, Fenwick JC, Wiggs BR, et al. Oxygen consumption is independent of increases in oxygen delivery by dobutamine in septic patients who have normal or increased plasma lactate. Am Rev Respir Dis. 1993;147:25-31.

7. Marik PE, Sibbald WJ. Effect of stored-blood transfusion on oxygen delivery in patients with sepsis. JAMA. 1993;269:3024-9.

8. Hayes MA, Timmins AC, Yau E, et al. Elevation of systemic oxygen delivery in the treatment of critically ill patients. N Engl J Med. 1994;330:1717-22.

9. Bellomo R, Di Giantomasso D. Noradrenaline and the kidney: friends or foes? Crit Care. 2001;5:294-8.

10. Paulson OB, Strandgaard S, Edvinsson L. Cerebral autoregulation. Cerebrovasc Brain Metab Rev. 1990;2:161-92.

11. Drummond JC. The lower limit of autoregulation: time to revise our thinking? (letter). Anesthesiology. 1997;86:1431-3.
12. Braunwald E, Sonnenblick EH, Ross J. Mechanisms of cardiac contraction and relaxation. In: Braunwald E, editor. Heart disease. Philadelphia: W.B.Saunders Company; 1988. p. 383-425.

13. Funk DJ, Jacobsohn E, Kumar A. The role of venous return in critical illness and shock-part I: physiology. Crit Care Med. 2013;41:250-7.

14. Guyton AC. Determination of cardiac output by equating venous return curves with cardiac response curves. Physiol Rev. 1955;35:123-9.

15. Gelman S. Venous function and central venous pressure: a physiologic story. Anesthesiology. 2008;108:735-48.

16. Peters J, Mack GW, Lister G. The importance of the peripheral circulation in critical illnesses. Intensive Care Med. 2001;27:1446-58.

17. Marik PE, Monnet X, Teboul JL. Hemodynamic parameters to guide fluid therapy. Ann Crit Care. 2011;1:1.

18. Bayliss WM, Starling EH. Obeservations on venous pressures and their relationship to capillary pressures. J Physiol. 1894;16:159-318.

19. Sheldon CA, Cerra FB, Bohnhoff N, et al. Peripheral postcapillary venous pressure: a new, more sensitive monitor of effective blood volume during hemorrhagic shock and resuscitation. Surgery. 1983;94:399-406.

20. Sheldon CA, Balik E, Dhanalal K, et al. Peripheral postcapillary venous pressure: a new hemodynamic monitoring parameter. Surgery. 1982;92:663-9.

21. Guyton AC, Lindsey AW, Kaufmann BN, et al. Effect of blood transfusion and hemorrhage on cardiac output and the venous return curve. Am J Physiol. 1958;194:263-7.

22. Rothe CF, Flanagan AD, Maass-Moreno R. Role of beta-adrenergic agonists in the control of vascular capacitance. Can J Physiol Pharmacol. 1990;68:575-85.

23. Datta P, Magder S. Hemodynamic response to norepinephrine with and without inhibition of nitric oxide synthase in porcine endotoxemia. Am J Respir Crit Care Med. 1999;160:1987-93.

24. Persichini R, Silva S, Teboul JL, et al. Effects of norepinephrine on mean systemic pressure and venous return in human septic shock. Crit Care Med. 2012;40:3146-53.

25. Monnet X, Jabot J, Maizel J, et al. Norepinephrine increases cardiac preload and reduces preload dependency assessed by passive leg raising in septic shock patients. Crit Care Med. 2011;39:689-94.

26. Jellinek H, Krafft P, Fitzgerald RD, et al. Right atrial pressure predicts hemodynamic response to apneic positive airway pressure. Crit Care Med. 2000;28:672-8.

27. Hirvonen EA, Poikolainen EO, Paakkonen ME, et al. The adverse hemodynamic effects of anesthesia, head-up tilt, and carbon dioxide pneumoperitoneum during laparoscopic cholecystectomy. Surg Endosc. 2000;14:272-7.

28. Kamenik M, Paver-Erzen V. The effects of lactated Ringer's solution infusion on cardiac output changes after spinal anesthesia. Anesth Analg. 2001;92:710-4.

29. van den Berg PC, Jansen JR, Pinsky MR. Effect of positive pressure on venous return in volume-loaded cardiac surgical patients. J Appl Physiol. 2002;92:1223-31.

30. Maas JJ, Pinsky MR, de Wilde RB, et al. Cardiac output response to norepinephrine in postoperative cardiac surgery patients: interpretation with veous return and cardiac function curves. Crit Care Med. 2013;41:143-50.

31. Cohn JN, Luria MH. Studies in clinical shoock and hypotension.ii. Hemodynamic effects of norepinephrine and angiotensin. J Clin Invest. 1965;44:1494-505.

32. Butterworth JF, Piccione W, Berrizbeitia LD, et al. Augmentation of venous return by adrenergic agonists during spinal anesthesia. Anesth Analg. 1986;65:612-6.

33. - Prowle JR, Echeverri JE, Ligabo EV et al. Fluid balance and acute kidney injury. Nat Rev Nephrol 2010; 6:107-15. This paper 
reviews the harm associated with volume overload as well as the pathophysiological consequences of a high venous pressure.

34. Winton FR. The influence of venous pressure on the isolated mamalian kidney. J Physiol. 1931;72:49-61.

35. Mullens W, Abrahams Z, Francis GS, et al. Importance of venous congestion for worsening of renal function in advanced decompensated heart failure. J Am Coll Cardiol. 2009;53:589-96.

36. Nohria A, Hasselblad V, Stebbins A, et al. Cardiorenal interactions: insights from the ESCAPE trial. J Am Coll Cardiol. 2008;51:1268-74.

37. Damman K, Navis G, Smilde TD, et al. Decreased cardiac output, venous congestion and the association with renal impairment in patients with cardiac dysfunction. Eur J Heart Fail. 2007;9:872-8.

38. Legrand M, Dupuis C, Simon C, et al. Association between systemic hemodynamics and septic kidney injury in critically ill patients: a retrospective observational study. Crit Care. 2013;17:R278.

39. Vellinga NA, Ince $C$, Boerma EC. Elevated central venous pressure is associated with impairment of microcirculatory blood flow in sepsis. BMC Anesthesiol. 2013;13:17.

40. Ueda S, Nishio K, Akai Y, et al. Prognostic value of increased plasma levels of brain natriuretic peptide in patients with septic shock. Shock. 2006;26:134-9.

41. Zhang Z, Zhang Z, Xue Y, et al. Prognostic value of B-type natriuretic peptide (BNP) and its potential role in guiding fluid therapy in critically ill septic patients. Scand J Trauma Resus Emerg Med. 2012;20:86.

42. Bruegger D, Jacob M, Rehm M, et al. Atrial natriuretic peptide induces shedding of endothelial glycocalyx in coronary vascular bed of guinea pig hearts. Am J Physiol Heart Circ Physiol. 2005;289:H1993-9.

43. Berg S, Golster M, Lisander B. Albumin extravasation and tissue washout of hyaluronan after plasma volume expansion with crystalloid or hypooncotic colloid solutions. Acta Anaesthesiol Scand. 2002;46:166-72.

44. Bruegger D, Schwartz L, Chappell D, et al. Release of atrial natriuretic peptide precedes shedding of the endothelial glycocalyx equally in patients undergoing on- and off-pump coronary artery bypass surgery. Basic Res Cardiol. 2011;106:1111-21.

45. • Jacob M, Chappell D, Rehm M. The 'third space'-fact or fiction? Best Practice \& Research 2009; Clinical Anaesthesiology. 23:145-57. This is an outstanding paper which reviews the role of the glycocalyx in maintaining vascular integrity and demonstrates that the "third space" is a space that does not exist.

46. Atchison DJ, Johnston MG. Atrial natriuretic peptide attenuates flow in an isolated lymph duct preparation. Eur $\mathrm{J}$ Physiol. 1996;431:618-24.

47. Anderson WD, Kulik TJ, Mayer JE, et al. Inhibition of contraction of isolated lymphatic ducts by atrial natriuretic peptide. Am J Physiol. 1991;260:R610-4.

48. Ohhashi T, Watanabe N, Kawai Y, et al. Effects of atrial natriuretic peptide on isolated bovine mesenteric lymph vessels. Am J Physiol. 1990;259:H42-7.

49. Chowdhury AH, Cox EF, Francis S, et al. A randomized, controlled, double-blind crossover study on the effects of 2-L infusions of $0.9 \%$ saline and plasma-lyte 148 on renal blood flow velocity and renal cortical tissue perfusion in healthy volunteers. Ann Surg. 2012;256:18-24.

50. Funk DJ, Jacobsohn E, Kumar A. Role of the venous return in critical illness and shock: Part II-shock and mechanical ventilation. Crit Care Med. 2013;41:255-62.

51. • Cecconi M, Aya HD, Geisen M et al. Changes in the mean systemic filling pressure during a fluid challenge in postsurgical intensive care patients. Intensive Care Med 2013; 39:1299-305. This is an elegant study that validates the concept of mean circulating filling pressure and the effects of the CVP on venous return and cardiac output.
52. Marik PE, Lemson J. Fluid responsiveness: an evolution of our understanding. Br J Anaesth. 2014;112:620-2.

53. Dellinger RP, Levy MM, Rhodes A, et al. Surviving sepsis campaign: international guidelines for management of severe sepsis and septic shock: 2012. Crit Care Med. 2013;41:580-637.

54. Initial Assessment and Management. Advanced Trauma Life Support for Doctors; Student course manual. 6th ed. Chicago: American College of Surgeons; 1997. p. 21-46.

55. Marik PE. Early management of severe sepsis: current concepts and controversies. Chest. 2014;145:1407-18.

56. Cecconi M, Corredor C, Arulkumaran N, et al. Clinical review: goal-directed therapy-what is the evidence in surgical patients? The effect on different risk groups. Crit Care. 2013;17:209.

57. - Corcoran T, Rhodes JE, Clarke S et al. Perioperative fluid management strategies in major surgery: A stratified meta-analysis. Anesth Analg 2012; 114:640-51. This meta-analysis demostrates the harm from a liberal fluid strategy in patients undergoing surgery.

58. Wang $\mathrm{CH}$, Hsieh $\mathrm{WH}$, Chou $\mathrm{HC}$, et al. Liberal versus restricted fluid resuscitation strategies in trauma patients: a systematic review and meta-analysis of randomized controlled trials and observational studies. Crit Care Med. 2014;42:954-61.

59. •- Maitland K, Kiguli S, Opoka RO et al. Mortality after fluid bolus in african children with severe infection. $\mathrm{N}$ Engl $\mathrm{J}$ Med 2011; 364:2483-95. This is a classic paper that highlights the increased risk of death in patients treated with an aggressive fluid resuscitation protocol.

60. Maitland K, George EC, Evans JA, et al. Exploring mechanisms of excess mortality with early fluid resuscitation: insights from the FEAST trial. BMC Med. 2013;11:68.

61. Latta TA. Relative to the treatment of cholera by the copious injection of aqueous and saline fluid into the veins. Lancet. 1832;2:274-7.

62. - Marik PE, Cavallazzi R. Does the central venous pressure (CVP) predict fluid responsiveness: An update meta-analysis and a plea for some common sense. Crit Care Med 2013; 41:1774-81. This meta-analysis demonstrates the failure of the CVP to predict fluid responsiveness.

63. Osman D, Monnet X, Castelain V, et al. Incidence and prognostic value of right ventricular failure in acute respiratory distress syndrome. Intensive Care Med. 2009;35:69-76.

64. Jardin F, Vieillard-Baron A. Ultrasonographic examination of the venae cavae. Intensive Care Med. 2006;32:203-6.

65. Vieillard-Baron A, Chergui K, Rabiller A, et al. Superior vena caval collapsibility as a gauge of volume status in ventilated septic patients. Intensive Care Med. 2004;30:1734-9.

66. Durairaj L, Schmidt GA. Fluid therapy in resuscitated sepsis: less is more. Chest. 2008;133:252-63.

67. De Backer D, Heenen S, Piagnerelli M, et al. Pulse pressure variations to predict fluid responsiveness: influence of tidal volume. Intensive Care Med. 2005;31:517-23.

68. Mahjoub Y, Pila C, Friggeri A, et al. Assessing fluid responsiveness in critically ill patients: false-positive pulse pressure variation is detected by Doppler echocardiographic evaluation of the right ventricle. Crit Care Med. 2009;37:2570-5.

69. Cannesson M, Le MY, Hofer CK, et al. Assessing the diagnostic accuracy of pulse pressure variations for the prediction of fluid responsiveness: a "gray zone" approach. Anesthesiol. 2011;115:231-41.

70. Cavallaro F, Sandroni C, Marano C, et al. Diagnostic accuracy of passive leg raising for prediction of fluid responsiveness in adults: systematic review and meta-analysis of clinical studies. Intensive Care Med. 2010;36:1475-83.

71. Monnet X, Rienzo M, Osman D, et al. Passive leg raising predicts fluid responsiveness in the critically ill. Crit Care Med. 2006;34:1402-7. 